\begin{tabular}{c|c|c}
\hline JURNAL PENELITIAN FARMASI HERBAL & VOL. 1 NO. 2 & $\begin{array}{c}\text { EDITION: NOVEMBER 2018 } \\
\text { APRIL 2019 }\end{array}$ \\
\hline & http://ejournal.delihusada.ac.id/index.php/JPFH & \\
\cline { 2 - 3 } RECEIVED: 17 FEBRUARI 2019 & REVISED: 20 MARET 2019 & ACCEPTED: 26 APRIL 2019 \\
\hline
\end{tabular}

\title{
UJI IMUNOSTIMULATOR DARI KOMBINASI EKSTRAK ETANOL HERBA BINARA (ARTEMISIA VULGARIS LINN) DAN EKSTRAK ETANOL DAUN PUCUK MERAH (SYZYGIUM OLEANA) DENGAN METODE HIPERSENSITIVITAS TIPE LAMBAT PADA TIKUS JANTAN
}

\author{
Romauli Anna Teresia Marbun, Aminah Syarifuddin, Montysory Silalahi, \\ Radika Bella Fista Ginting \\ Institut Kesehatan Medistra Lubuk Pakam, Jalan Sudirman No. 38 Lubuk Pakam \\ e-mail : romamarbun60@yahoo.com
}

\begin{abstract}
One of the herbs used is herbal binara (Artemisia vulgaris $L$ ) which has been studied as a potential immunomodulator with high antioxidant activity. Previous research also stated that red shoots (Syzygium oleana) were studied as potential immunomodulators with high antioxidant activity. Several other species such as Syzygium samarangense have 16 flavonoida compounds which show pharmacological immunological activity. The purpose of this study was to determine the content of secondary metabolites of ethanol extract of herbal binara (Artemisia vulgaris L.) with red shoots (Syzygium oleana) and to determine the best dose of extract from the ethanol extract of herbal binara (Artemisia vulgaris L.) with red shoots (Syzygium oleana) can reduce the volume of swelling of mouse feet. Examination of the chemical content of secondary metabolites from the ethanol extract of herbal binara (Artemisia vulgaris L.) with red shoots (Syzygium oleana) is carried out by chemical screening and characterization of simplicia and extract. The method used is the slow type hypersensitivity method. In this test the independent variable is the secondary metabolite of ethanol extract of herb binara (Artemisia vulgaris L.) with red shoots (Syzygium oleana) with four concentrations (50, 100, 200 and $400 \mathrm{mg} / \mathrm{kgBB}$ ). The positive control used by Stimuno dose is $32.5 \mathrm{mg} / \mathrm{kgBB}$.
\end{abstract}

Keywords: Imuno stimulator, Ekstrak Etanol, hipersensitivitas

\section{PENDAhUluan}

Indonesia sebagai salah satu negara dengan keanekaragaman hayati yang sangat melimpah dan merupakan peluang bagi para peneliti khususnya yang bergerak dalam bidang eksprlorasi, inventarisasi dan perkembangan obat hayati dan nabati. Untuk menjelajah dan mengeskplorasi kekayaan tersebut dalam rangka menemukan senyawa baru, spesies baru bahkan senyawa bioaktif baru yang diantaranya diharapkan sebagai obat bagi beberapa penyakit yang sampai saat ini belum ditemukan obatnya (Krensky et al., 2012).
Obat tradisional Indonesia merupakan warisan budaya bangsa sehingga perlu dilestarikan, diteliti dan dikembangkan. Penelitian obat tradisional Indonesia mencakup penelitian obat herbal tunggal maupun dalam bentuk ramuan. Jenis penelitian yang telah dilakukan selama ini meliputi penelitian budidaya tanaman obat, analisis kandungan kimia, toksisitas, farmakodinamik, formulasi, dan uji klinik (Dewoto, 2007).

Suatu zat yang berperan sebagai penambah atau peningkat imun dapat diperoleh dengan penggunaan herbal yang berkhasiat sebagai imunostimulan. Salah satu herbal yang digunakan adalah herba binara 


\begin{tabular}{|c|c|c|}
\hline JURNAL PENELITIAN FARMASI HERBAL & VOL. 1 NO. 2 & $\begin{array}{c}\text { EDITION: NOVEMBER 2018 } \\
\text { APRIL 2019 }\end{array}$ \\
\hline & http://ejournal.delihusada.ac.id/index.php/JPFH & \\
\cline { 2 - 2 } & REVISED: 20 MARET 2019 & ACCEPTED: 26 APRIL 2019 \\
\hline RECEIVED: 17 FEBRUARI 2019 &
\end{tabular}

(Artemisia vulgaris L) yang diteliti berpotensi sebagai imunomodulator dengan aktivitas antioksidan yang tinggi (Marbun et al., 2018). Penelitian sebelumnya juga menyatakan bahwa daun pucuk merah (Syzygium oleana) diteliti berpotensi sebagai imunomodulator dengan aktivitas antioksidan yang tinggi. Beberapa spesies lain seperti Syzygium samarangense memiliki 16 senyawa flavonoida yang menunjukkan aktivitasimunologi secara farmakologi. Uji fitokimia telah dilaporkan bahwa pada daun pucuk merah mengandung kardenolin, saponin, flavonoid (Helmi, 2016).

\section{METODE}

Penelitian ini merupakan penelitian eksperimental yang menggunakan tikus jantan sebagai hewan percobaan untuk melihat efek imunostimulatorherba binara (Artemisia vulgaris L.) dengan tumbuhan pucuk merah (Syzygium oleana)pada tikus jantan.

Pengujian imunomodulator yang digunakan adalah hipersensitivitas tipe lambat dan uji analisa data. Penelitian ini dilakukan di laboratorium Biologi, laboratorium Farmakologi di Fakultas Farmasi Institut Kesehatan MEDISTRA Lubuk pakam.

\section{Alat}

Alat-alat yang digunakan dalam penelitian ini adalah alat-alat gelas laboratorium, aluminium foil, neraca listrik (Vibra), seperangkat alat destilasi penetapan kadar air, rotary evaporator, blender (National), mortir dan stamfer, neraca hewan, spuit 1 $\mathrm{ml}$ (Terumo), oral sonde, pletismometer air raksa, velocity $18 \mathrm{R}$ refrigerated centrifuge (Dynamic), microtube, microtitration plate, micropipette (Socorex), dan kertas saring.

\section{Bahan}

Bahan-bahan yang digunakan dalam penelitian ini adalah herba binara (Artemisia vulgaris L.) dengan tumbuhan pucuk merah (Syzygium oleana), karboksi metil selulosa
(CMC), inokulum e.coli, natrium klorida $(\mathrm{NaCl})$, kalium klorida $(\mathrm{KCl})$, dinatrium hidrogen fosfat, Stimuno, $\left(\mathrm{Na}_{2} \mathrm{HPO}_{4}\right)$, kalium dihidrogen fosfat $\left(\mathrm{KH}_{2} \mathrm{PO}_{4}\right)$, aqua bidestilasi, heparin, etanol $96 \%$, toluen, kloroform dan air suling.

\section{Pengambilan Sampel}

Pengumpulan sampel dilakukan secara purposif yaitu tanpa membandingkan dengan tumbuhan yang sama dari daerah lain. Bagian yang digunakan adalah ekstrak etanol herba binara (Artemisia vulgaris L.) dengan tumbuhan pucuk merah (Syzygium oleana). Pengambilan sampel dilakukan di tebing tinggi.

\section{Pembuatan Simplisia}

Herba binara (Artemisia vulgaris L.) dengan tumbuhan pucuk merah (Syzygium oleana) dibersihkan dari pengotoran dengan cara mencuci di bawah air mengalir hingga bersih, ditiriskan lalu ditimbang sebagai berat basah, selanjutnya dikeringkan di lemari pengering $\left( \pm 50^{\circ} \mathrm{C}\right)$. Setelah kering, Herba binara (Artemisia vulgaris L.) dengan tumbuhan pucuk merah (Syzygium oleana) ditimbang kembali lalu diserbuk hingga halus. Serbuk simplisia dimasukkan ke dalam wadah plastik bertutup, dan disimpan pada suhu kamar.

\section{Pembuatan Ekstrak Etanol}

Sebanyak $1 \mathrm{~kg}$ serbuk simplisia herba binara (Artemisia vulgaris L.) dengan tumbuhan pucuk merah (Syzygium oleana) dimasukkan ke dalam bejana tertutup, ditambahkan 7,5 liter etanol $96 \%$ lalu bejana ditutup dan dibiarkan selama 5 hari terlindung dari cahaya sambil sering diaduk. Kemudian disaring dan ampas dibilas kembali dengan etanol 96\% hingga diperoleh 100 bagian. Maserat ditampung pada botol gelap, dibiarkan di tempat sejuk dan terlindung dari cahaya selama 2 hari kemudian disaring. Kemudian ekstrak dipekatkan dengan menggunakan rotary evaporator. Masingmasing ekstrak dikeringkan dengan freeze dryer (Depkes RI, 1979). 


\section{Pembuatan Suspensi Ekstrak Etanol Herba Binaradengan Tumbuhan Pucuk Merah (Syzygium Oleana)}

Dalam pengujian akan digunakan 4 variasi dosis yakni dosis 50, 100, 200, dan 400 $\mathrm{mg} / \mathrm{kgBB}$. Ditimbang $50 \mathrm{mg}$ Ekstrak Etanol Herba binara (Artemisia vulgaris L.) dengan tumbuhan pucuk merah (Syzygium oleana). Dimasukkan ke dalam lumpang, kemudian tuang sedikit demi sedikit suspensi CMC $\mathrm{Na}$ $0,5 \%$ sambil digerus hingga homogen, setelah homogen dituangkan ke dalam labu tentukur $100 \mathrm{ml}$. Demikian dengan variasi dosis 100, 200, dan $400 \mathrm{mg} / \mathrm{kgBB}$.

\section{Penyiapan Hewan Percobaan}

Hewan uji yang digunakan adalah tikus jantan sebanyak 25 ekor dengan berat 150 200 gram. Sebelum perlakuan, hewan percobaan dikondisikan terlebih dahulu selama 2 minggu dalam kandang yang baik untuk menyesuaikan lingkungannya dan menyeragamkan makanan.

\section{Penyiapan Kontrol, Suspensi Stimuno $\AA_{\text {, }}$ Inokulum Bakteri Dan Uji Hipersensitivitas Tipe Lambat}

Uji hipersensitivitas tipe lambat meliputi penyiapan kontrol suspensi CMC Na 0,5\%, suspensi Stimuno ${ }^{\circ}$, penyiapan suspensi ekstrak herba binara (Artemisia vulgaris L.) dengan tumbuhan pucuk merah (Syzygium oleana), dan inokulum.

\section{Uji Hipersensitivitas Tipe Lambat}

Efek imunostimulator ekstrak etanol herba binara (Artemisia vulgarisL.) dengan tumbuhan pucuk merah (Syzygium oleana) ditentukan menggunakan uji respon hipersensitivitas tipe lambat dengan cara mengukur volume pembengkakan telapak kaki hewan uji (foot paw swelling test) (Krensky, 2012). Hewan dikelompokkan sebagai berikut:

Kelompok I diberi sediaan suspensi CMC Na 0,5\%; Kelompok II diberi sediaan suspensi Stimuno ${ }^{\circledR} \quad 32,5 \mathrm{mg} / \mathrm{kg} \quad B B$; Kelompok III diberi sediaan suspensi EEHB dengan EEPM dengan dosis $50 \mathrm{mg} / \mathrm{KgBB}$; Kelompok IV diberi sediaan suspensi EEHB dengan EEPM dengan dosis $100 \mathrm{mg} / \mathrm{KgBB}$; Kelompok $V$ diberi sediaan suspensi EEHB dengan EEPM dengan dosis $200 \mathrm{mg} / \mathrm{KgBB}$; Kelompok VI diberi sediaan suspensi EEHB dengan EEPM dengan dosis $400 \mathrm{mg} / \mathrm{KgBB}$.

Tiap kelompok hewan percobaan diinjeksikan dengan $0,1 \mathrm{ml}$ inokulum bakteri e.coli secara i.p (intraperitonium) sebagai antigen pada hari ke-0. Perlakuan dimulai dari hari ke-0 da diberikan satu kali setiap hari selama 7 hari. Pada hari ke-7, sendi kaki tikus sebelah kanan diberi tanda batas pengukuran volume kaki tikus. Volume kaki tikus diukur sebagai volume awal (V0).

Kemudian tikus diinjeksikan dengan $0,1 \mathrm{ml}$ inokulum bakteri e.coli secara intraplantar pada telapak kaki sebelah kanan. Pada hari kedelapan (setelah 24 jam) diukur volume pembengkakan kaki tikus dengan pletismometer air raksa. Pengukuran dilakukan dengan mencelupkan kaki tikus ke dalam tabung yang berisi air raksa sampai tanda batas pengukuran. Perubahan volume air raksa terlihat pada kenaikan skala pletismometer sebagai volume waktu tertentu (Vt) kaki tikus. Volume pembengkakan kaki tikus ditentukan berdasarkan selisih antara volume waktu tertentu (Vt) dengan volume awal (V0).

\section{HASIL DAN PEMBAHASAN}

Data hasil penelitian dianalisis dengan menggunakan program SPSS. Data hasil penelitian ditentukan homogenitas dan normalitasnya untuk menentukan analisis statistik yang digunakan. Data dianalisis dengan menggunakan uji ANAVA satu arah untuk menentukan perbedaan rata-rata diantara perlakuan. Jika terdapat perbedaan, dilanjutkan dengan menggunakan uji Post Hoc Tuckey untuk mengetahui variabel mana yang memiliki perbedaan. Berdasarkan nilai signifikansi $p<0,05$ dianggap signifikan. 


\begin{tabular}{c|c|c}
\hline JURNAL PENELITIAN FARMASI HERBAL & VOL. 1 NO. 2 & $\begin{array}{c}\text { EDITION: NOVEMBER 2018 - } \\
\text { APRIL 2019 }\end{array}$ \\
\hline & http://ejournal.delihusada.ac.id/index.php/JPFH & \\
\cline { 2 - 3 } RECEIVED: 17 FEBRUARI 2019 & REVISED: 20 MARET 2019 & ACCEPTED: 26 APRIL 2019 \\
\hline
\end{tabular}

\section{Pemeriksaan Serbuk Simplisia}

Tabel 1 Hasil pemeriksaan karakterisasi serbuk simplisia herba binara.

\begin{tabular}{|c|c|c|}
\hline Parameter & $\begin{array}{c}\text { Simplisia } \\
\text { Herba Binara } \\
\text { \% }\end{array}$ & $\begin{array}{c}\text { Standart MMI } \\
\text { Binara \% }\end{array}$ \\
\hline $\begin{array}{c}\text { Kadar Air } \\
\text { Kadar Sari Larut Dalam } \\
\text { Air }\end{array}$ & 16 & $<10$ \\
\hline $\begin{array}{c}\text { Kadar Sari Larut Dalam } \\
\text { Etanol }\end{array}$ & 9,66 & $>5,0$ \\
\hline Kadar Abu Total & 4,33 & $<13$ \\
\hline $\begin{array}{c}\text { Kadar Abu Tidak Larut } \\
\text { Asam }\end{array}$ & 0,66 & $<1,5$ \\
\hline
\end{tabular}

Keterangan : Materia Medika Indonesia (MMI) (Depkes RI, 1989).

Tabel 2 Hasil pemeriksaan karakterisasi serbuk simplisia ekstrak etanol Daun pucuk merah (syzygium oleana).

\begin{tabular}{|c|c|c|}
\hline Parameter & $\begin{array}{c}\text { Simplisia } \\
\text { Herba Binara } \\
\text { \% }\end{array}$ & $\begin{array}{c}\text { Standart MMI } \\
\text { Binara \% }\end{array}$ \\
\hline $\begin{array}{c}\text { Kadar Air } \\
\text { Kadar Sari Larut Dalam } \\
\text { Air }\end{array}$ & 13 & $<10$ \\
\hline $\begin{array}{c}\text { Kadar Sari Larut Dalam } \\
\text { Etanol }\end{array}$ & 9,66 & $>5,0$ \\
\hline Kadar Abu Total & 3,24 & $<13$ \\
\hline $\begin{array}{c}\text { Kadar Abu Tidak Larut } \\
\text { Asam }\end{array}$ & 1,2 & $<1,5$ \\
\hline
\end{tabular}

\section{Uji Respon Hipersensitivitas Tipe} Lambat

Ekstrak etanol herba binara (EEHB) dengan ekstrak etanol puCuk merah (EEPM) menunjukkan aktivitas imunomodulator khususnya sebagai imunostimulan. Volume awal (Vo) pembengkakan pada kaki tikus setelah diinduksi bakteri E.coli secara intraperitonium yaitu : CMC-Na 0,5\% 2,280 $\mathrm{ml}$, EEHB dengan EEPM dosis $50 \mathrm{mg} / \mathrm{kgBB}$ 2,300 $\mathrm{ml}$, EEHB dengan EEPM dosis 100 $\mathrm{mg} / \mathrm{kgBB} 2,320 \mathrm{ml}$, EEHB dengan EEPM dosis $200 \mathrm{mg} / \mathrm{kgBB} 2,300 \mathrm{ml}$, EEHB dengan EEPM dosis $400 \mathrm{mg} / \mathrm{kgBB} \quad 2,450 \mathrm{ml}$ dan Stimuno®32,5 mg/kgBB 2,380 ml.

Volume akhir (Vt) pembengkakan pada kaki tikus setelah diinduksi bakteri E.coli secara intraplantar yaitu : CMC-Na 0,5\% 2,620 ml, EEHB dengan EEPM dosis $50 \mathrm{mg} / \mathrm{kgBB} 3,260$ $\mathrm{ml}$, EEHB dengan EEPM dosis $100 \mathrm{mg} / \mathrm{kgBB}$ $3,580 \mathrm{ml}$, EEHB dengan EEPM dosis 200 $\mathrm{mg} / \mathrm{kgBB} 3,760 \mathrm{ml}$, EEHB dengan EEPM dosis $400 \mathrm{mg} / \mathrm{KgBB} \quad 3,760$ mldan Stimuno $(32,5$ $\mathrm{mg} / \mathrm{kgBB} 3,210 \mathrm{ml}$.

Rentang perbedaan volume pembengkakan volume (Vt-Vo) pada kaki tikus yaitu : CMC$\mathrm{Na}$ 0,5\% 0,240 ml, EEHB dengan EEPM dosis $50 \mathrm{mg} / \mathrm{kgBB} 0,860 \mathrm{ml}$, EEHB dengan EEPM dosis $100 \mathrm{mg} / \mathrm{kgBB} 1,180 \mathrm{ml}$, EEHB dengan EEPM dosis $200 \mathrm{mg} / \mathrm{kgBB} 1,360 \mathrm{ml}$, EEHB dengan EEPM dosis $400 \mathrm{mg} / \mathrm{KgBB} 1,40 \mathrm{ml}$ dan Stimuno ${ }^{\circ} 32,5 \mathrm{mg} / \mathrm{kgBB} 1,300 \mathrm{ml}$.

Tabel 3 Volume pembengkakan kaki tikus.

\begin{tabular}{|c|c|c|c|c|}
\hline \multirow{2}{*}{ No } & \multirow{2}{*}{ Perlakuan } & \multicolumn{3}{|c|}{ Volume Kaki Tikus (ml) } \\
\hline & & Vo & $\mathrm{Vt}$ & $\Delta \mathrm{V}$ \\
\hline \multirow{5}{*}{1} & \multirow{5}{*}{$\begin{array}{l}\mathrm{CMC}-\mathrm{Na} \\
0,5 \%\end{array}$} & 2,2 & 2,5 & 0,3 \\
\hline & & 2,4 & 2,7 & 0,3 \\
\hline & & 2,3 & 2,6 & 0,3 \\
\hline & & 2,2 & 2,6 & 0,4 \\
\hline & & 2,3 & 2,7 & 0,4 \\
\hline \multirow{5}{*}{2} & \multirow{5}{*}{$\begin{array}{l}\text { Stimuno }{ }^{\circledR} \\
32,5 \mathrm{mg} / \mathrm{kg} \\
\text { BB }\end{array}$} & 2,3 & 3,1 & 0,8 \\
\hline & & 2,2 & 3,1 & 0,9 \\
\hline & & 2,4 & 3,3 & 0,9 \\
\hline & & 2,3 & 3,2 & 0,9 \\
\hline & & 2,3 & 3,1 & 0,8 \\
\hline \multirow{5}{*}{3} & \multirow{5}{*}{$\begin{array}{l}\text { EEHB dengan } \\
\text { EEPM } 50 \\
\mathrm{mg} / \mathrm{kg} \mathrm{BB}\end{array}$} & 2,3 & 3,5 & 1,4 \\
\hline & & 2,3 & 3,4 & 1,2 \\
\hline & & 2,2 & 3,4 & 1,2 \\
\hline & & 2,4 & 3,6 & 1,2 \\
\hline & & 2,4 & 3,5 & 1,1 \\
\hline \multirow{5}{*}{4} & \multirow{5}{*}{$\begin{array}{l}\text { EEHB dengan } \\
\text { EEPM } 100 \\
\mathrm{mg} / \mathrm{kg} \mathrm{BB}\end{array}$} & 2,3 & 3,7 & 1,4 \\
\hline & & 2,3 & 3,6 & 1,4 \\
\hline & & 2,2 & 3,5 & 1,3 \\
\hline & & 2,3 & 3,7 & 1,4 \\
\hline & & 2,4 & 3,8 & 1,6 \\
\hline \multirow{5}{*}{5} & \multirow{5}{*}{$\begin{array}{l}\text { EEHB dengan } \\
\text { EEPM } 200 \\
\mathrm{mg} / \mathrm{kg} \mathrm{BB}\end{array}$} & 2,3 & 3,4 & 1,1 \\
\hline & & 2,2 & 3,5 & 1,3 \\
\hline & & 2,2 & 3,6 & 1,4 \\
\hline & & 2,3 & 3,7 & 1,4 \\
\hline & & 2,4 & 3,7 & 1,3 \\
\hline \multirow{5}{*}{6} & \multirow{5}{*}{$\begin{array}{l}\text { EEHB dengan } \\
\text { EEPM } 400 \\
\mathrm{mg} / \mathrm{kg} \mathrm{BB}\end{array}$} & 2,4 & 3,7 & 1,3 \\
\hline & & 2,5 & 3,6 & 1,1 \\
\hline & & 2,5 & 3,8 & 1,3 \\
\hline & & 2,4 & 3,7 & 1,3 \\
\hline & & 2,4 & 3,8 & 1,4 \\
\hline
\end{tabular}

Keterangan :

V0 $=$ Volume awal kaki tikus

$\mathrm{Vt}=$ Volume pembengkakan kaki tikus $\Delta \mathrm{V}=$ Selisih antara volume waktu akhir (Vt) dengan volume awal (V0) 


\begin{tabular}{c|c|c}
\hline JURNAL PENELITIAN FARMASI HERBAL & VOL. 1 NO. 2 & $\begin{array}{c}\text { EDITION: NOVEMBER 2018 - } \\
\text { APRIL 2019 }\end{array}$ \\
\hline & http://ejournal.delihusada.ac.id/index.php/JPFH & \\
\cline { 2 - 3 } RECEIVED: 17 FEBRUARI 2019 & REVISED: 20 MARET 2019 & ACCEPTED: 26 APRIL 2019 \\
\hline
\end{tabular}

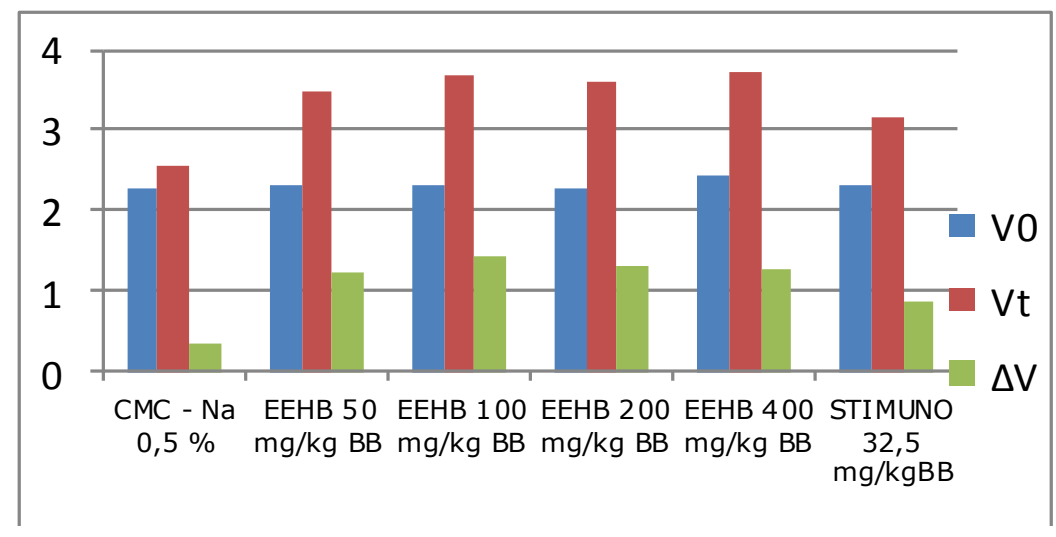

Gambar 1. Volume pembengkakan kaki tikus

Pada Tabel 2 dan Gambar 1 terlihat bahwa EEHB dosis $200 \mathrm{mg} / \mathrm{kgBB}$ dengan volume pembengkakan $1,360 \mathrm{ml}$ menunjukkan volume pembengkakan lebih besar dibandingkan dengan EEHB dosis 50, 100 $\mathrm{mg} / \mathrm{kgBB}$ dan suspensi imboost 32,5 $\mathrm{mg} / \mathrm{kgBB}$ yang masing-masing bernilai 0,860 $\mathrm{ml}, 1,180 \mathrm{ml}$ dan $1,300 \mathrm{ml}$. Hasil uji ANOVA menunjukkan $P<0,000$ yang artinya terdapat perbedaan signifikan volume pembengkakan kaki tikus $(P<0,05)$.

\section{KESIMPULAN}

Pemeriksaan kandungan kimia metabolit sekunder dari ekstrak etanol binara herbal (Artemisia vulgaris L.) dengan tunas merah (Syzygium oleana) dilakukan dengan penyaringan kimia dan karakterisasi simplisia dan ekstrak. Metode yang digunakan adalah metode hipersensitivitas tipe lambat. Dalam tes ini variabel independen adalah metabolit sekunder dari ekstrak etanol ramuan binara (Artemisia vulgaris L.) dengan tunas merah (Syzygium oleana) dengan empat konsentrasi (50, 100, 200 dan $400 \mathrm{mg} / \mathrm{kgBB})$. Kontrol positif yang digunakan oleh dosis Stimuno adalah $32,5 \mathrm{mg} / \mathrm{kgBB}$.

\section{DAFTAR PUSTAKA}

Aldi, Rasyadi, Y., dan Handayani, D. (2014). Aktivitas Imunomodulator dari Ekstrak Etanol Meniran (Phyllanthus niruri Linn.) terhadap Ayam Broiler. Jurnal Sains Farmasi dan Klinis Fakultas Farmasi. 1(1): 20-26.

Baratawidjaja, K. (2012). Imunologi Dasar. Edisi ke IX. Yogyakarta: Balai Penerbit
Fakultas Kedokteran Universitas Indonesia. Halaman 418.

Dewoto, H.R., 2007, Pengembangan Obat Tradisional Indonesia menjadi Fitofarmaka, Majalah kedokteran indonesia, 57(7): 205-211.

Helmi, A.F. (2016). Ekstrak etanol daun pucuk merah (Syzygium olena) sebagai inhibitor korosi baja dalam medium asam klorida.Jurnal farmakologi. 1(1): 20-26.

Krensky, A.M., Strom, B.T., dan Bluestone, A.J. (2012). Imunomodulator: Senyawa Imunosupresif, Tolerogen, dan Imunostimulan. Jakarta: Penerbit Buku Kedokteran EGC. Halaman 14351436

Kresno, B.S. (2001). Imunologi: Diagnosis dan Proses Laboratorium. Edisi keempat. Jakarta: Balai Penerbit Fakultas Kedokteran Universitas Indonesia. Halaman 5, 10-12.

Marbun, R., Situmorang, N., \& Wahyuni, S. (2018). The effect of immunomodulator by extract ethanol of herba binara (artemisia vulgaris I.) Toward the response of delayed-type hypersensitivity in rat male. Jurnal Penelitian Farmasi \& Herbal, 1(1), 1721.

Roma marbun . (2018). Immunomodulatory effects of ethanol extract artemisia vulgaris I. In male rats. Asian journal of pharmaceutical and clinical research. 11(1): 245-240. 